\title{
sciendo
}

DOI 10.2478/sbe-2019-0030

SBE no. 14(2) 2019

\section{CONSUMER RESISTANCE TO INNOVATION IN THE FASHION INDUSTRY}

\section{PUIU IONELA-ANDREEA \\ The Bucharest University of Economic Studies, Romania}

\begin{abstract}
:
Innovation is considered an essential point of market competitivity and industrial dynamics. However, there is one main reason that delays or inhibits the innovation spread, the consumer resistance to innovation. Innovation resistance of the consumers has undergone less consideration to describe and forecast adoption-related behaviour. The actual paper develops and empirically validates a scale that intends to measure consumers' inclination to resist innovation that emerge from people's tendency to resist changes and manifest status-quo satisfaction when it's related to fashion items. The scale describes a measure of the inclination to the status-quo option, even if people are satisfied with existing fashion items or with the degree of innovation in the fashion industry.
\end{abstract}

Key words: Innovation Resistance; Status-quo Bias; Fashion Industry; Exploratory Factor Analysis; Structural Equation Modelling

\section{Introduction}

Every day many innovative goods and services are released in the market. In a world of changes, where the cycles of innovation process have shortened, industries faced increased pressure to put unique services and products in the market. Nevertheless, more than half of the new goods and services launched in the market fail to achieve commercial advantage (Castellion and Markham, 2013).

Multiple aspects limit a new good or service from transforming into an innovation, like a high price, inferior quality of the product or new characteristics that customers are reluctant to spend money for (Garcia et al., 2007). Despite these factors, there is one main reason that is insufficiently discussed by the innovation diffusion theory - resistance to innovation manifested by the consumer (Kleijnen et al., 2009).

Resistance to innovation can occur from various determinants, from the violation of a current belief system, an unwillingness to embrace behavioral adjustments linked with innovation adoption or because of the noticed risks associated with the innovation. One research considers that innovation resistance is determined by an irrational and negatively 
biased evaluation of innovation as cognitive resistance to change (Stryja and Satzger, 2018). Consumers, often, minimizes the potential of existed options which transpires in an irrational resistance behavior.

Decision-making process often diverges from the accepted normative standards of rational homo economicus. Even if heuristics, mental short-cut processes, help people to deal with complex decision-making in daily life, the cognitive inclinations which misrepresent rational individual often end in suboptimal choices. The present paper intends to acquire a better understanding of the innovation resistance process and to investigate the influence of the status-quo preference when it's related to fashion products, as the main feature that reduces the likelihood of innovation adoption

\section{Literature Review}

\section{Conceptual Framework}

Innovation is considered the central point of economic changes. According to the Oxford English Dictionary, innovation refers to the action or process of innovating (1), or to a new method, product or idea (2). Innovation overlaps design and creativity, requiring the application, implementation and explanation of new ideas to deliver an intended result, new customer, new markets, bigger markets or competitive advantage.

The innovation chain model (Kline and Rosenberg, 1986) conceptualizes innovation in terms of the interaction between market opportunities and the company's knowledge or capabilities. Even though innovation is the lifeblood of most organizations (Balachandra and John, 1997), there is one main reason that delays or inhibits the innovation spread, the consumer resistance to innovation.

In the specific literature, the distinction between refinement or improvement of an existing design and the introduction of a new concept, which significantly departs from existing practices, describes an essential assumption in the literature on innovation (Henderson and Clark, 1990). Thus, we distinguish between three levels of innovation, incremental innovations, radical innovations and disruptive innovations.

Incremental innovations describe companies that are producing something they are already good at but improve incrementally. They perform tasks a little bit better each time when they launch a new version of an existing product. In general, companies are very good at incremental innovations. On the other side, we have the radical innovations, described as the innovations that create significant changes in society (Schumpeter, 1934). This kind of innovation does not occur with regularity in a company life cycle, but it does happen. The last level of innovation, disruptive innovation, focuses on the consequences of innovation. The disruptive innovation usually starts in a niche market.

\section{Understanding the Innovation-Decision Process}

Resistance to innovation is described as a negative response of individuals to innovation, due to the potential of changing their default option (status-quo bias), contradicting the beliefs structures of actors involved in economic transactions (Ram and Sheth, 1989). 
Researchers believe that resistance to innovation causes consumers to manifest three types of attitudes: rejection, postponement of adoption or opposition to it (Kleijnen et al., 2009). Some studies in the area point that resistance to innovation is an instinctive, natural response of the consumers (Ram and Sheth, 1989), while another study considers resistance as a default option of the human behavior (Cornescu and Adam, 2013).

Recent studies recognized two main categories of factors that determine resistance to innovation: innovations that ask for a change in already established behavioral patterns: customs, norms, traditions and innovations that cause conflict or complication at the psychological level of consumers (Kleijnen et al., 2009). Psychological barriers are represented by conflicts that a consumer experiences when innovation demands changing existing beliefs or deviating from rules and traditions.

The fundamental structure of the innovation-decision process follows the five stages introduced by Rogers (2003): knowledge stage, then persuasion, decision, implementation and confirmation stages. In the knowledge stage the consumer is exposed to the innovation, he becomes aware of it. This information should drive him to explore additional information related to the innovation characteristics and to continue to the persuasion stage, where the he forms his approving or hostile attitude regarding innovation. In the third stage, the consumer decides whether to adopt or to reject the innovation. In the implementation stage, intentions transform into actual behavior. In the confirmation stage, the consumer continues, stops or reverses his behavior if he is exposed to conflicting information regarding the innovation.

Concerning the contextual factors, the decision process depends on three contextual determinants. The first one is related to adopter-specific factors, and here we include cognitive rigidity, risk aversion and involvement. The second contextual factor refers to situation-specific circumstances, such as the shopping environment or budget restrictions, while the third contextual factor is related to innovation circumstances like attributes of the new product, complexity or compatibility.

\section{Active and Passive Innovation Resistance}

It was realized a distinction between active innovation resistance (Kleijnen et al., 2009; Nabih et al., 1997), described by the adoption of a rejection attitude following to the product evaluation, and passive innovation resistance (Patsiotis et al., 2013; Nabih et al., 1997) characterized by an unfavorable attitude that precedes product evaluation.

Active innovation resistance it's a deliberate form of resistance, consumers developing their attitudes toward innovation taking into consideration the evaluation of the product attributes (Rogers, 2003). The innovation specific barriers are of two types (Antioco and Kleijnen, 2010; Ram and Sheth, 1989); functional barriers, that occur when the consumer realizes that product attributes are dysfunctional, inadequate or conflicting with his personal needs and usage expectations, and psychological barriers that arise when innovation conflicts with a consumer's social norms, values or it's perceived as being too risky.

On the other hand, the passive innovation resistance emerges from adopter specific factors that determine the individuals' related disposition to oppose changes (Antón et al., 2013; Sheth, 1981) and situation-specific determinants that cause the status- 
quo satisfaction (Claudy, 2011). In the case of the passive innovation resistance, opposition manifests to the changes required by the innovation, not to the innovation itself, the nonpurchase behavior being adopted without a preliminary deliberative evaluation of the novel product.

In their research Ram (1987) and Sheth (1981) point out that status-quo satisfaction drives passive innovation resistance that may influence people's desire to make changes in their life. Many researchers pointed out that the status-quo is an essential reference point for people, determining them to prefer the current situation, even if an alternative option would provide them with a higher utility. In line with the Prospect Theory (Kahneman and Tversky, 1979) it's argued that goods already owned by an individual represent a reference point in the innovation-decision process. Because people are emotionally connected to the products they own, when they are exposed to change, they favor already tested goods.

In their research, Talke and Heidenreich (2014) propose a ranking of the passive innovation resistance according to status-quo satisfaction and capacity to resist changes. Dual passive resistance to innovation appears when a person is deeply inclined to resist changes and extremely satisfied with the product he uses. A low passive resistance leads to favorable conditions for new product evaluation. Cognitive passive innovation is managed by the individual's inclination to resist changes, while situational passive resistance is generated by individual status-quo satisfaction when he deals with new products on the market.

In the paper is intended to investigate whether the consumer is biased to the status-quo option if he is both highly satisfied with actual products and the extent of innovation. According to the specific literature (Talke and Heidenreich, 2014) a passive innovation resistance is, among other factors, determined by the situation-specific statusquo satisfaction (SQS) affecting the consumer desire to change. Also, status-quo it's an important reference point in the decision process, in such a way, that people tend to prefer already tried products instead of new ones, even if the alternative would provide them with a higher utility because, in general, people experience an emotional attachment to the product they possess (Kahneman and Tversky, 1979).

Also, the innovation evolves very fast, many alternatives are available and often becomes difficult for the consumer to make a fast and accurate comparison of the existing products. Consequently, consumers become oversaturated with innovations, lowering their receptiveness to alternatives and increase preferences for the status-quo (Claudy, 2011).

So, the status-quo satisfaction comprises two features, satisfaction with existing products (SQSP) and satisfaction with the extent of innovation (SQSI) (Talke and Heidenreich, 2014).

\section{Hypothesis}

Hypothesis A: There are two features of the status-quo satisfaction, namely the satisfaction with existing products (SQSP) and the satisfaction with the extent of innovation (SQSI) when it comes to fashion items. 
Hypothesis B: There is a positive relationship among the obtained factors and socio-demographic variables such as the age of the respondents, they're employment state, and they're place of residence.

\section{Methodology}

The Instrument and the Method of Analysis:

The method of analysis used in the present paper has at its base a questionnaire, that intends to measure the situation-specific status-quo satisfaction related to fashion items. The questionnaire contains six statements related to fashion and clothing. Each item is measured on a seven-point Likert scale. All items were positive, and the scoring was one - for strongly disagree and seven - for strongly agree. The collected results would be analyzed using an exploratory analysis, then the results would be checked using a confirmatory analysis and a structural equation modelling, all analysis being performed in the $\mathrm{R}$ programming and statistical software.

\section{Sample and Data Collection:}

To realize the exploratory factor analysis was collected a pilot sample consisting of 31 respondents (gender: female - 19; male - 12, residence: urban - 21, rural - 10; age: 18-25 years - 17 respondents, 25-35 years - 11 respondents, 36-45 years - 3 respondents).

Subsequent, the final data consists of 128 responses, collected via Google Forms Application from December 2018 to January 2019. Respondents with ages among $18-45$ were the target of the research. To obtain a sample that is not biased, participants were picked from private and public Romanian faculties. As we can see from the data (Table 1), we have recorded more responses from females. A possible explanation can be that females were recognized as the main purchasing agents of clothing items for themselves and their household members (Fuller and Blackwell, 1992).

Table 1. Demographic Information

\begin{tabular}{ccc}
\hline Variable & Categories & $\mathrm{N}=128$ \\
\hline \multirow{3}{*}{ Age } & $18-25$ years & 82 \\
& $26-35$ years & 30 \\
Gender & 36-45 years & 16 \\
& Male & 40 \\
Residence & Female & 88 \\
& Urban & 109 \\
\cline { 2 - 3 } Studies & Rural & 19 \\
& High School & 47 \\
& College & 13 \\
& Bachelor's Degree & 27 \\
& Master's Degree & 28 \\
\cline { 2 - 3 } & Phn Stılias & 8
\end{tabular}



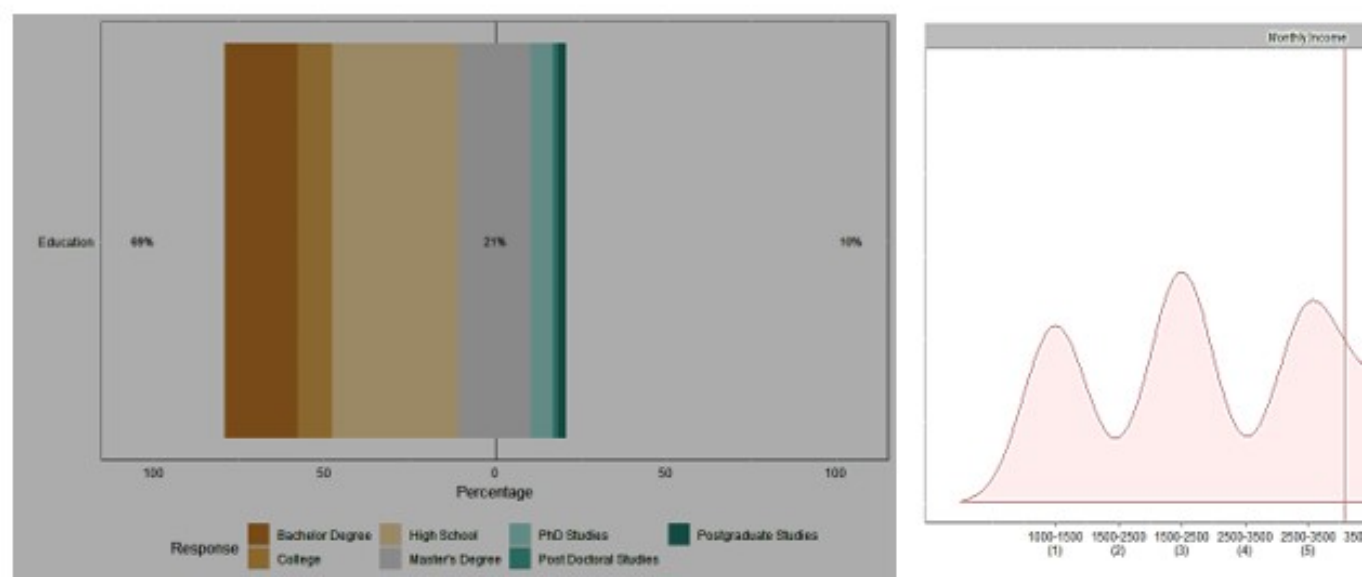

As we can see from the first graph (Fig. 1), we encounter mostly respondents that reported the last level of graduate education as being high school or bachelor's degree. According to the graphical representation of the net monthly earnings, the mean of the respondent's income seems to be around the value of 3000 lei (Fig. 2).

\section{Data Analysis:}

To perform the exploratory factor analysis, I checked pilot sample for the reliability using Cronbach's alpha metric. The most frequently used method of reliability (internal consistency) Cronbach alpha was first developed by Kuder and Richardson (1937) for binomial data and later it was generalized by Cronbach (1951), to account for any scoring method. To conduct a reliability analysis in $\mathrm{R}$, the data must have an unidimensional scale, identical loadings and no correlations should exist, assumptions that are fulfilled.

The specific literature states that the Cronbach's alpha indicator is desired to register values above 0.7 in the case of exploratory analysis, value above 0.8 in the case of basic analysis, and values above 0.9 for an applied scenario (Cortina, 1993). In the present analysis, I have recorded a raw alpha score of 0.80 for the SQSI dimension and an alpha score of 0.93 for the SQSP dimension. According to the specific literature, those are good scores for exploratory analysis.

The exploratory factor analysis is based on factor rotation. In this way all items loading on all factors, the main objective being to pick a rotation that gives the closest approximation to the simple structure, clear factors, easily interpretable, fewest crossloadings (Osborne, 2014). We judge the model fit based on the conducted scree plots and interpretability of the model, choosing the factor rotation that makes the factors more interpretable, taking into consideration that the main ground for factor rotation is that the solution is non-unique, aspect known as the "ambiguousness" of factor analysis (Druică, 2018).

Broadly speaking, the most common assumptions of exploratory factor analysis are multivariate normality, homoscedasticity, linearity and continues variables. The first step, in the factor analysis, will consist of a visual representation of the covariances among variables, we need most of the values to be between 0.3 and 0.7 . If we register values lower than 0.3 , the variables are not quite correlated, therefore, we cannot expect them to measure similar dimensions. On the other hand, correlations higher than 0.7 indicates that we have multicollinearity in the data. In both cases, our estimators will be biased (Druică et 
al., 2011). From the graph (Fig. 3) can be seen that variables co-variate mainly because one variable influence another and because both variables are underlined by a similar source that is not explicitly mentioned.

The purpose of the applied factor analysis is to estimate a model able to explain covariances between a set of observed variables using a set of unobserved variables called factors.

According to the present model, status-quo alternative, a main cause for passive innovation resistance, has two manifest variables; satisfaction with the extent of innovation and satisfaction with existing products. The two manifest variables share status-quo alternative as a common cause, although status-quo alternative cannot explain their entire variability. Status-quo alternative it's a latent variable, that can be measured only through its manifestations.

$$
Y=\mu+\lambda^{*} F+\varepsilon \text { Equation }
$$

In general terms, in the equation $Y$ stands for the observed variable, $\lambda$ represents the factor loading and in a standardized form is the slope in a correlation metric. $F$ is the factor, and $\varepsilon$ represents the disturbance arising from other influences than shared factors (unique factors). The factor loading $(\lambda)$ reflects the contribution of the factor on each observed variable.
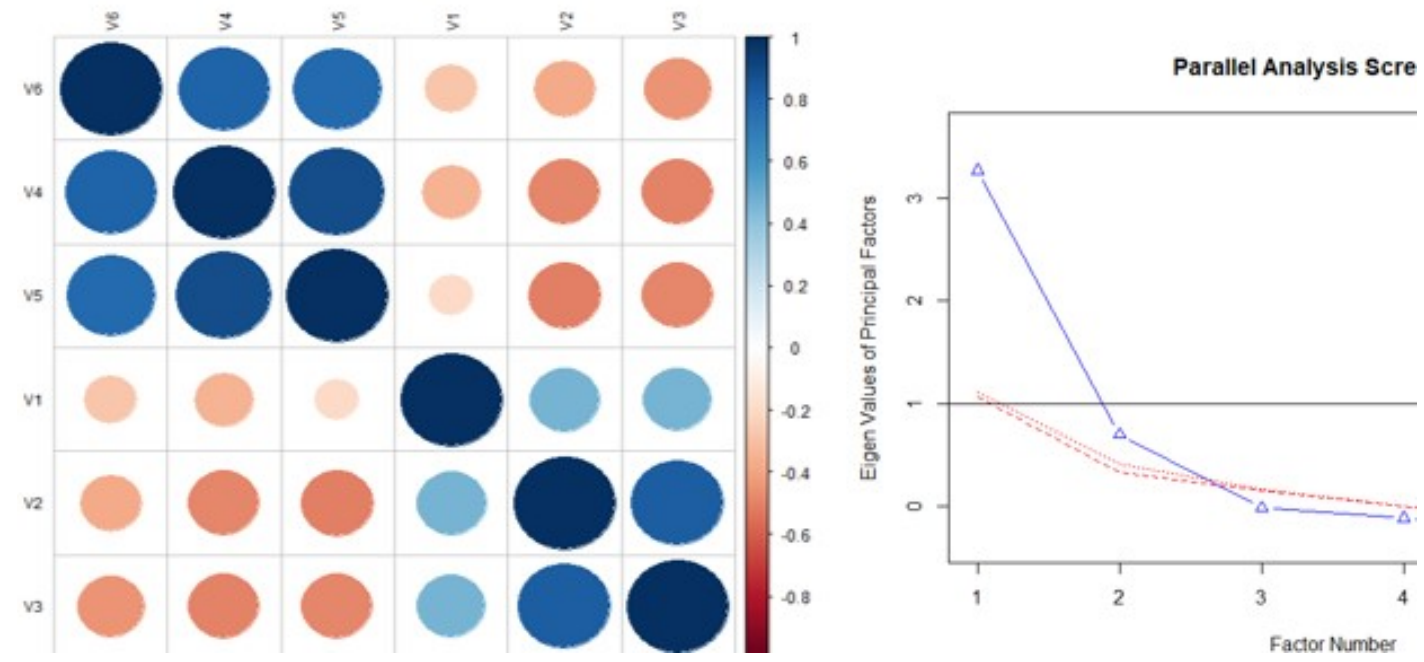

I have applied the Bartlett's Test of Sphericity that tests whether the correlation matrix is significantly different from the corresponding identity matrix. If there is no difference, then there are no significant correlations between our observed variables, so the exploratory factor analysis does not make any sense.

The null hypothesis of this test states that the correlation matrix is not different than the corresponding identity matrix. After running the test, the obtained p-value is lower than 0.05 , allowing us to reject the null hypothesis and to assume that the correlation matrix is different than the corresponding identity matrix.

The parallel function from the psych $\mathrm{R}$ package (Revelle, 2018) identifies the ideal number of factors. According to the previous figure (Fig. 4), it seems that two factors are enough. 
Therefore, I compute a factor analysis with an oblique rotation, that usually applies to factors that are not independent, to reduce covariance of squared loadings between factors.

In what concern the fit indices related to the user model versus the baseline model we have the Tucker-Lewis Index that identifies overly complex models. A value above 0.95 is desired, in this model being registered a value of 0.952 .

From the R output, I have extracted the root mean square error of approximation (RMSEA) that refers to residuals and measures how a model generates wrong patterns. The cut-off is 0.08 and, in this case, the RMSEA registers a value of 0.134 , below the cutoff. The standardized root mean square residual (SRMR) registers a value below the 0.08 cut-off (Marsh et al. 2004) recording a value of 0.03 (Table 2).

Table 2. Factor Loadings, Fit Indices and Information Criteria ITEM

\begin{tabular}{|c|c|}
\hline \multirow{3}{*}{$\begin{array}{c}\text { F2 } \\
\text { Satisfaction } \\
\text { with the } \\
\text { Extent of } \\
\text { Innovation } \\
\text { (SQSI) }\end{array}$} & $\begin{array}{l}\text { My personal need for innovations in the field of fashion products has } \\
\text { been by far not covered in the past. }\end{array}$ \\
\hline & $\begin{array}{l}\text { I consider the number of innovations in the field of fashion products } \\
\text { being too low. }\end{array}$ \\
\hline & $\begin{array}{l}\text { I consider the pace of innovations in the field of fashion products as bei } \\
\text { too low. }\end{array}$ \\
\hline \multirow{5}{*}{$\begin{array}{c}\text { F1 } \\
\text { Satisfaction } \\
\text { with Existing } \\
\text { Products } \\
\text { (SQSP) }\end{array}$} & In the past, I was very satisfied with available fashion products. \\
\hline & In my opinion, past fashion products were completely satisfactory so fa \\
\hline & Past fashion products fully met my requirements. \\
\hline & FIT INDICES \\
\hline & er-Lewis Index (TLI) \\
\hline
\end{tabular}

From the table (Table 2) it can be observed that the factor loading for the second question on the first factor is 0.811 , meaning that for each unit increase in the latent perceived factor, the model predicts a 0.811 increase in the second variable. The factor loading, or the weights of each observed variable in producing a score representing the factor, could present negative or positive signs and high loadings suggest stronger factor contributions to the analysed variables.

Further, I plot the loadings of each factor, and as noted previous, higher loadings are desired (Fig. 5). We observe that the registered factor loadings have high scores indicating that there is a high degree to which the variables are caused by the factor. Finally, were represented in a graphical format the obtained factors. As we can see (Fig. $6)$, each factor is composed of three items.

Even if the exploratory analysis generates satisfying results, the probability that the results are context or sample-specific cannot be removed. Therefore, it was performed a confirmatory factor analysis to verify the results.

It was applied the Cronbach's alpha test and for the sample consisting of 128 respondents. This time there was recorded an alpha score of 0.76 for the SQSI dimension and an alpha score of 0.91 for the SQSP dimension.

Further, the confirmatory analysis was performed using the lavaan package (Yves, 2012) implemented in $R$ and the maximum likelihood estimator (ML) 
In terms of the overall goodness of fit, the chi-square test registers a p-value of 0.340, greater that the 0.05 threshold, the Comparative Fit Index and Tucker-Lewis index registered scores higher than 0.95 cut-off, respectively 0.998 and 0.995 . In the case of the RMSEA and SRMR the registered values were lower than 0.80 cut-off.
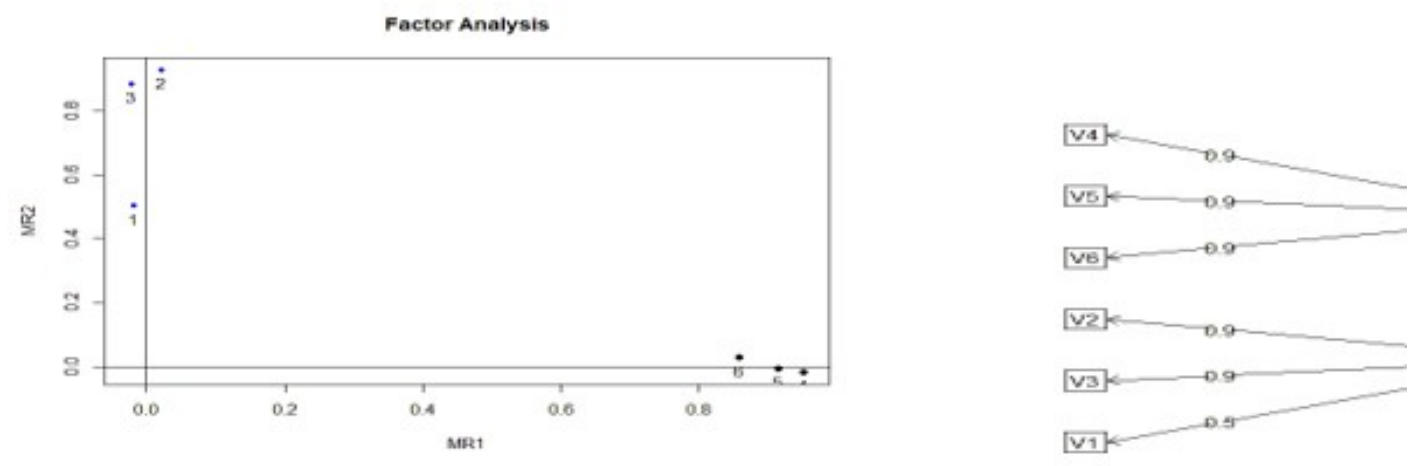

Table 3.CFA Model

\begin{tabular}{cccccccc}
\hline Latent Factor & Indicator & Intercepts & Estimator & Std.Err & Z & P-value & Beta \\
\hline F1 & V1 & 3.882 & 0.618 & 0.132 & 4.683 & 0 & 0.416 \\
F1 & V2 & 3.937 & 1.308 & 0.139 & 9.388 & 0 & 0.833 \\
F1 & V3 & 3.787 & 1.446 & 0.133 & 10.9 & 0 & 0.968 \\
F2 & V4 & 4.276 & 1.323 & 0.105 & 12.659 & 0 & 0.902 \\
F2 & V5 & 4.291 & 1.291 & 0.103 & 12.59 & 0 & 0.898 \\
F2 & V6 & 4.11 & 1.214 & 0.106 & 11.411 & 0 & 0.841 \\
\hline
\end{tabular}

Source: own calculation

In the previous table (Table 3 ) there are listed the parameters of the specified model, we can observe that all factor loadings have significant score and the p-value is very low in all cases. Also, the intercept estimator is like an intercept in regular regression model and it gives the expected value for the variables when all predictors are at zero.

Further, I investigate if there is any relationship between the obtained factor and respondents' age, their employment state or their place of residence. To do this, I performed a structural equation modelling, a very general statistical modelling technique widely used in behavioral sciences, developed by Sewall Wright in 1921. This method can be described as a mixture of factor analysis and regression or path analysis and its interest it's on the theoretical constructs, designed by the latent factors. The relationships developed among the theoretical constructs are represented by regression or path coefficient between the factors (Hox and Bechger, 1999).

In the model, I used three different formula types: latent variable definitions, regression formulas and residual correlations. To perform the function, I used the lavaan package (Yves, 2012) implemented in the R library.

The output revealed that the fit indices register desired values for a good fit. The null hypothesis $\left(\mathrm{H}_{0}\right)$ of the chi-squared test states that the model fits perfectly. In the case of the performed structural equation modelling, the obtained p-value is 0.366 , higher than the 0.05 threshold. Therefore, we fail to reject the null hypothesis. 
Table 4. Fit Indices

\begin{tabular}{cccc}
\hline Measure & Name & Value & Cut_off \\
\hline X2 & Model Chi-Square & 0.366 & p-value $>0.05$ \\
GFI & Goodness of fit & 0.948 & GFI $>=0.95$ \\
AGFI & Adjusted Goodness of fit & 0.883 & AGFI $>=0.90$ \\
NFI & Normed Fit-Index & 0.952 & NFI $>=0.95$ \\
\hline (NNFI) TLI & Tucker-Lewis Index & 0.994 & (NNFI) TLI $>=0.95$ \\
CFI & Comparative Fit Index & 0.996 & CFI $>=0.90$ \\
RMSEA & Root Mean Square Error of Approximation & 0.025 & RMSEA $<0.08$ \\
SRMR & (Standardized) Root Mean Square Residual & 0.036 & SRMR $<0.08$ \\
\hline
\end{tabular}

Source: own calculation

'Realized using <htmlTable $>$ function in R

Furthermore, for the goodness of fit index (GFI) the cut-off value is 0.95 . In this model, the goodness of fit index registers a value of 0.948 , below the threshold. Regarding the adjusted goodness of fit (AGFI), the obtained value is 0.883 , below the 0.90 thresholds. The normed fit index (NFI) cut-off for a good fit is 0.95 (Kline, 2016), in this case registering a value of 0.952 , above the cut-off. On the other hand, for the non-normed fit index (known as Tucker-Lewis Index) the obtained value is 0.994 , above the threshold.

In the case of the comparative fit index, the cut-off value for the good fit is 0.90 , in the present analysis registering a score of 0.996. Regarding the root mean square error of approximation (RMSEA), the obtained value should be lower than the 0.08 threshold, in this case registering a value of 0.025 . In the case of the standardized root mean square residuals (SRMR) the obtained value is 0.036 , lower than the 0.08 cut-off.

\begin{tabular}{l|c|c|c}
$\begin{array}{l}\text { Dependent } \\
\text { Dariable }\end{array}$ & $\begin{array}{c}\text { Table 5. Regressions with Factors } \\
\text { Independent } \\
\text { Variable }\end{array}$ & \multicolumn{2}{c}{ Estimate } \\
\hline \multirow{5}{*}{ Factor 1 } & Age & -0.189 & \\
\cline { 2 - 4 } & Employment & 0.220 & \\
\cline { 2 - 4 } Factor 2 & Residence & 0.024 & \\
\cline { 2 - 4 } & Age & 0.114 & \\
\cline { 2 - 4 } & Employment & 0.261 & \\
\cline { 2 - 4 } & Residenre & $-n n \Delta 2$ &
\end{tabular}

In the case of the performed regressions with factors, the independent variables are dummy variables. So, in the case of the age variable, I noted with zero respondents with ages among 18-25 years, and with one the respondents with ages among 26-45 years. In the case of the place of residence, I note urban area with one and rural area with zero, while in the case of the employment state of the respondents, I note with zero respondents who are not employed and with one the respondents who are employed.

As we can see from the previous table, in the case of the first factor, namely satisfaction with existing products, the age variable presents a negative sign. If the respondent is aged between $26-45$ years, the impact on the first factor is decreasing by 0.189 (Table 5). The p-value is high, so the variable doesn't have a statistically significant influence on the first factor. 
In the case of the employment state of the respondents, if the respondent is employed, the satisfaction with existing products is increasing by 0.220 . Again, the $p$-value is not statistically significant. Regarding, the impact of the place of residence on the first factor, if the respondent is from the urban area, the influence on the first factor is 0.024 . Again, the $p$-value is higher than the 0.05 threshold.

Concerning the second factor, we agree that the place of residence influences in a negative way the satisfaction with the extent of innovation. If the respondent is from urban area, the satisfaction with the extent of innovation is decreasing by 0.042 . The $p$-value is high; therefore, the statistical significance is low.

Regarding the age variable, if the respondent is aged between 26-45 years old, the satisfaction with the extent of innovation is increasing by 0.114 . The $p$-value is higher than the 0.05 threshold. Moreover, if the respondent is employed the satisfaction with the extent of innovation is increasing by 0.261 . The $p$-value is high; therefore, the statistical significance is low.

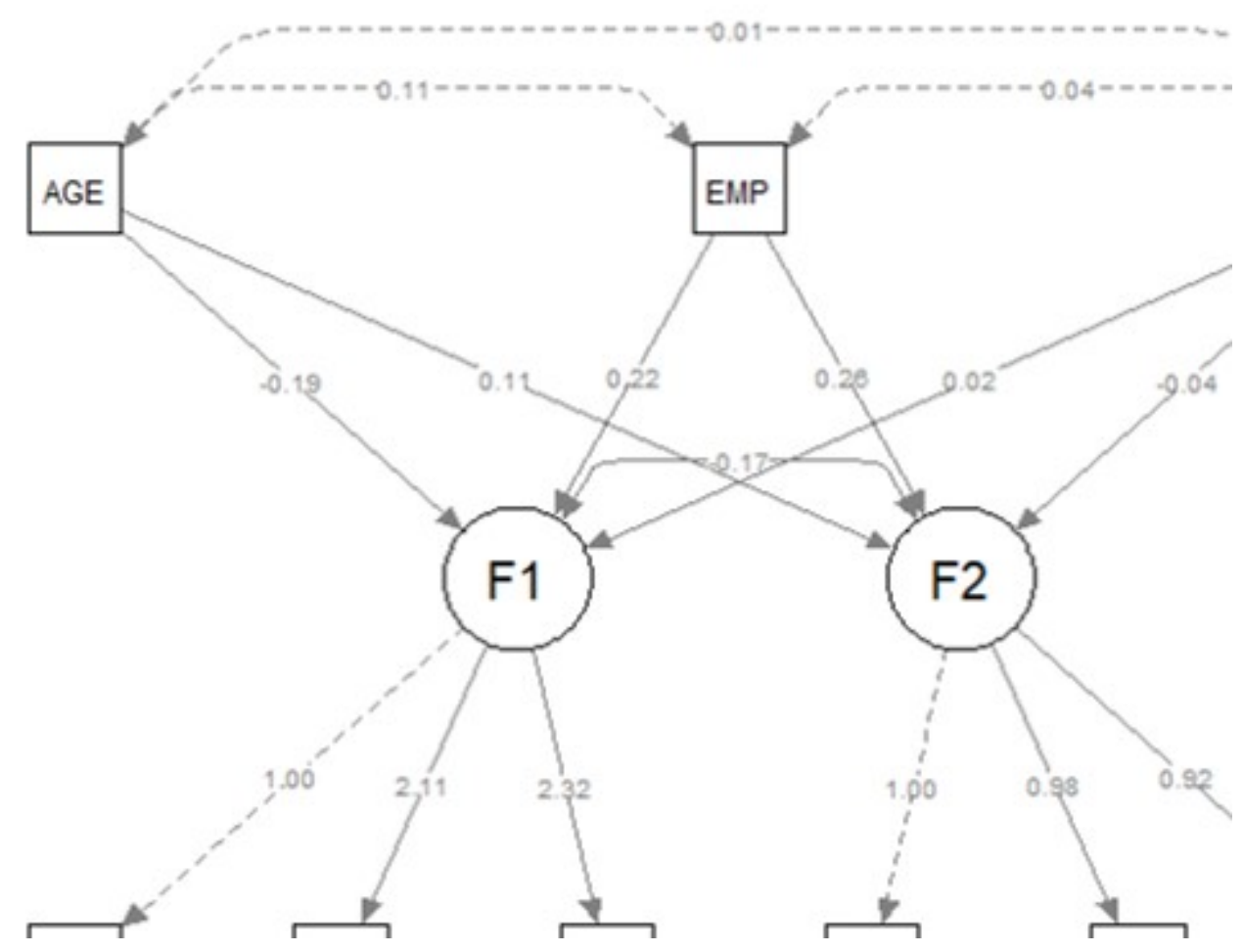

Applying the SemPath function, I represented in a graphical format the result of the structural equation modelling. As can be observed, from the previous figure, we have two factors ( $f 1$ and f2) and six variables, three for each factor. Each factor has an operator, that give us the loading for each indicator, on its factor. The factor loading for the second variable on the satisfaction with existing products is 2.11 , that means for each unit increase in the latent satisfaction with existing products factor, the model prognosticates a 2.11 increase on the second variable (Fig. 7).

In the end, there are represented the estimators of the regressions among each factor and dummy variables, previously discussed, age, employment state and place of residence. Also, the covariance between factors registers a negative value of -0.167 . 


\section{Conclusions}

The central aim of the present research was to get a better understanding of the innovation resistance behavior when it's related to the adoption of fashion products. Also, it was intended to develop and empirically validate a scale that aims to measure consumers' inclination to resist innovations, rising from people tendency to resist changes and exhibit status-quo satisfaction, when it's related to fashion products.

The conducted exploratory analysis revealed that the status-quo, an essential factor that determines passive innovation resistance, has two manifest variables; satisfaction with the extent of innovation and satisfaction with existing products. The registered factor loadings present high scores, indicating that there is a high degree to which the variables are caused by the factor. So, was identified that the status-quo satisfaction is mainly recognized through his manifestations, satisfaction with existing products and satisfaction with the extent of innovation.

Regarding the confirmatory factor analysis, the fit indices revealed the good performance of the model and the stability of the scale developed.

In the case of the structural equation modelling was intended to conduct regressions between the obtained factors and respondents' age, employment state or they're place of residence.

The analysis revealed that, in the case of the first factor, namely satisfaction with existing products, the age presents a negative sign, meaning that if the respondent it's aged between 26-45 years, the impact of the variable on the first factor is decreasing by 0.189 , but the relationship it's not statistically significant. In the case of the place of residence variable and employment state, we encounter a positive influence, but again the relationship it's not statistically significant.

Regarding the second factor, employment state and age variables exhibit a positive impact, but again the registered p-value is higher than 0.05 threshold. The place of residence presents a negative sign.

There are some limitations of this research that should be borne in mind when generalizing the findings from this study. The first limit on the present paper is represented by the sample. The sample is a segment of the statistical population chosen to represent it, the representativity of the sample assuring the accuracy of the estimation made based on calculating the research indicators and the inferential statistics (Hapenciuc, 2005). To respect the random nature of the sample formation, the sampling procedure should not be influenced by the analyst. However, in the present research, the sample it's a self-selected one and, in this case, the capacity to generalize the obtained results to the entire population is decreasing. Also, the sample is biased, we have more female respondents than male and more respondents from the urban area of living than from rural area.

On the other hand, as many studies have designated over time, structural models represent a typical approximation of reality (MacCallum, 2013). The structural model is approximated by omitting parameters that are involved in the causal process or other features of the model. This kind of omission performs a baffling representation of the estimation method, usually resulting in biased parameter estimates and inaccurate measurements of the standard errors (Tomarken and Waller, 2005). In the case of the structural model, even a very solid theoretical background can suit poorly and lead to biased estimates. 


\section{Acknowledgement}

This paper was co-financed by The Bucharest University of Economic Studies during the PhD program.

\section{References}

Antioco, M., Kleijnen, M., (2010), Consumer adoption of technological innovations: Effects of psychological and functional barriers in a lack of content versus a presence of content situation. European Journal of Marketing, Vol. 44, no. 11/12, pp. 1700-24.

Antón, C., Camarero, C., Rodríguez, J., (2013), Usefulness, enjoyment, and self-image congruence: The adoption of e-book readers. Psychology and Marketing, Vol. 30, no. 4, pp. 372-84.

Balachandra, R., John, F.H., (1997), Factors for success in R\&D projects and new product innovation: A contextual framework, IEEE Transactions on Engineering Management, pp. 276-287.

Castellion, G., Markham, S. K., (2013), Perspective: new product failure rates: influence of argumentum ad populum and self-interest. Journal of Product Innovation Management, Vol. 30, no. 5, pp. 976- 979.

Claudy, M., (2011), An empirical investigation of consumer resistance to green product innovation. Doctoral thesis, Dublin Institute of Technology, Dublin.

Cornescu, V., Adam, R., (2013), The Consumer Resistance Behaviour towards Innovation. Procedia Economics and Finance, no. 6, pp. 457-465.

Cortina, J.M., (1993), What is Coefficient Alpha: An Examination of Theory and Applications? Journal of Applied Psychology, no.78, pp. 98-104.

Druică, E., (2018), Research Methods in Behavioural and Experimental Economics. Exploratory Factor Analysis [Lecture].

Druică, E., Druică, I., lanole, R., Sandu, M., (2011), Statistică pe înțelesul tuturor. Editura C.H. Beck: București.

Fuller, B.K., Blackwell, S.C., (1992), Wardrobe consultant clientele: Identifying and describing three market segments. Clothing and Textiles Research Journal, Vol. 10, no. 2, pp. 11-17.

Garcia, R., Bardhi, F., Friedrich, C., (2007), Overcoming consumer resistance to innovation. MIT Sloan Management Review, Vol. 48, no. 4, pp. 82-88.

Hapenciuc, V., (2015), Procedee de eșantionare aplica în cercetarea pieței și administrarea eficientă a afacerilor. Retrieved from Universitatea Ștefan cel Mare din Suceava: http://www.seap.usv.ro/ valentinh/capitol\%203.pdf .

Henderson, R., Clark, K., (1990), Architectural Innovation: The Reconfiguration of Existing Product

Technologies and the Failure of Established Firms. Administrative Science Quarterly, Vol. 35, no. 1, pp. 9-30.

Hox, J., Bechger, T., (1999), An Introduction to Structural Equation Modelling. Family Science Review, no. 11, pp. 354-373.

Kahneman, D., Tversky, A., (1979), Prospect theory: An analysis of decision under risk. Econometrica, no. 47, pp. 263-91.

Kleijen, M., Lee, N.J., Wetzels, M., (2009), An exploration of consumer resistance to innovation and its antecedents. Journal of Economic Psychology, Vol. 30, no. 3, pp. 344-357.

Kline, R.B., (2016), Principles and Practice of Structural Equation Modelling. Fourth Edition. The Guilford Press: New York.

Kline, S.J., Rosenberg, N., (1986), An Overview of Innovation.

MacCallum, R.C., Widaman, K.F., Zhang, S.B., Hong, S.H., (1999), Sample size in factor analysis.

Psychological Methods, Vol. 4, no. 1, pp. 84-99.

Marsh, H. W., Hau, K.T., Wen, Z., (2004), In Search of Golden Rules: Comment on HypothesisTesting Approaches to Setting Cutoff Values for Fit Indexes and Dangers in Overgeneralizing. Hu and Bentler's Findings (1999). Structural Equation Modelling, Vol. 11, no. 3, pp. 320-341.

Nabih, M.I., Bloem, J.G., Poiesz, T.B.C., (1997), Conceptual issues in the study of innovation adoption behaviour. Advances in Consumer Research, Vol. 24, no.1, pp. 190-96.

Osborne, W.J., (2014), Best Practices in Exploratory Factor Analysis. Scotts Valley, CA: CreateSpace Independent Publishing. 
Patsiotis, A. G., Hughes, T., Webber, D.J., (2013), An examination of consumers' resistance to computer- based technologies. Journal of Services Marketing, Vol. 27, no. 4, pp. 294311.

Ram, S., (1987), A model of innovation resistance. Advances in Consumer Research, Vol. 14, no.1, pp. 208-12.

Ram, S., Sheth, N.J., (1989), Consumer Resistance to Innovations: The Marketing Problem and its solutions. Journal of Consumer Marketing, Vol. 6, no. 2, pp. 5-14.

Revelle, W., (2018), psych: Procedures for Personality and Psychological Research, Northwestern

University, Evanston, Illinois, USA, https://cran.r-project.org/web/packages/psych/ Version $=1.8 .12$

Rogers, E. M., (2003), Diffusion of innovations. NewYork: The Free Press.

Schumpeter, J., (1934), The Theory of Economic Development, Harvard University Press, Cambridge, Massachusetts.

Sheth, J.N., (1981), Innovation resistance. The less developed concept (LDC) in diffusion research. Research Vol. 4, pp. 273-82.

Stryja, C., Satzger, G., (2018), Digital nudging to overcome cognitive resistance in innovation adoption decisions. The Service Industries Journal.

Talke, K., Heidenreich, S., (2014), How to Overcome Pro-Change Bias. The Journal of Product Innovation Management, Vol. 31, no. 4, pp. 894-907.

Tomarken, A., Waller, G.N., (2005), Structural Equation Modelling: Strengths, Limitations, and Misconceptions. Annual review of clinical psychology. Vol. 1, pp. 31-65.

Yves, R., (2012), lavaan: An R Package for Structural Equation Modelling. Journal of Statistical $\begin{array}{llllll}\text { Software, } \quad \text { Vol. } 48, & \text { no. } 2, & \text { pp. } & 1-36 . & \text { URL: }\end{array}$ https://www.jstatsoft.org/article/view/v048i02. 